\title{
EVALUATION OF BOVIE GAMMA-INTERFERONE AND TUBERCULIN TEST FOR THE DIAGNOSIS OF BOVINE TUBERCULOSIS
}

\author{
ATTIA E.R.H ${ }^{1}$; GOMAA, A.M. ${ }^{1}$; MOSALLAM T.E. ${ }^{1}$; MOHAMED EL-DIASTY ${ }^{2}$; \\ SHERIF H.M. ${ }^{1}$; MANAL B.M. ${ }^{1}$ and HEBA A. AHMED ${ }^{2}$ \\ ${ }^{1}$ Animal Reproduction Research Institute (ARRI) \\ ${ }^{2}$ Animal Health Research Institute (AHRI)
}

Received: 10 June 2018; Accepted: 11 July 2018

\begin{abstract}
The study was conducted in 3 farms in Behera, Matrouh and Dakahlya provinces. These organized farms did not have previous records on animals with confirmed $M$. bovis infection as the herd had been previously skin tested. A total of 1323 animals of 1 year old and above were included in the study. All animals under our experiment were examined using Tuberculin Test; the positive cases were examined using T.B. Feron Test. The positive cases in both tests were slaughtered for PM and some samples were taken for bacteriological examination on specific media. Confirmation of the isolates by real time PCR. The results revealed that the number of total tested cattle by tuberculin were 1323 the positive were $357(27 \%)$ by tuberculin test, then tested by bovine gamma-interferon ( $\gamma$-IFN) enzyme immunoassay, the positive were $212(16 \%)$, in the first farm the tested cattle were 120 animals and the positive were $79(6 \%)$ by tuberculin test, then tested by bovine gamma-interferon $(\gamma$ IFN) enzyme immunoassay, the positive were $46(3.5 \%)$, the second farm the tested cattle were 520 and the positive reactors for tuberculin test were $274(20.7 \%)$, then tested by bovine gamma-interferon $(\gamma$-IFN) enzyme immunoassay, the positive were $166(12.5 \%)$ and the third farm the tested cattle were 683 and the positive cases were 4 animals $(0.3 \%)$ by tuberculin test, then tested by bovine gamma-interferon $(\gamma$-IFN) enzyme immunoassay and all the samples gave negative results. It is important to increasingly focus resources to target control strategies based on more effective diagnostic methods so the usage of T.B. Feron for detection of T.B. is more useful. And also the usage of T.B. Feron test to differentiate between vaccinated and infected cattle.
\end{abstract}

Key words: Tuberculosis, Gamma Interferone, Cattle, Elisa

\section{INTRODUCTION}

Tuberculosis (TB) is a major health problem throughout the world and represents the most frequent cause of death for a single infectious agent worldwide (Khalili et al., 2010). It is a chronic debilitating disease in cattle, but it can occasionally be acute and rapidly progressive. In the late stages, common symptoms including progressive emaciation, lowgrade fluctuating fever, weakness, and inappetence are observed. Animals with pulmonary involvement usually have a moist cough that is worse in the morning, during cold weather or exercise, and may have dyspnea or tachypnea (Une and Mori, 2007). Infection leads to a decrease in milk production (10$20 \%$ ), loss of weight, reduction of fertility and condemnation of carcasses of infected animals (Collins, 2006).

Latent tuberculosis infection (LTBI), a noncommunicable asymptomatic condition, might

Corresponding author: Dr. Mosallam T.E.

E-mail address: tarekelsayedmosallam@yahoo.com

Present address: Animal Reproduction Research Institute (ARRI) develop tuberculosis disease months or years later. The main purpose of LTBI diagnosing is to consider medical treatment for preventing tuberculosis disease (Ferrara et al., 2005).

Several methods have been used for the diagnosis of bovine TB (BTB), such as direct detection of the etiologic agent in biological material (for instance; culture and molecular assays), or in the indirect detection through the identification of a host immune response to the etiologic agent (for instance; tuberculin test and interferon-gama) (De la RuaDomenech et al., 2006; Schiller et al., 2010).

Isolation of $M$. bovis is considered the "gold standard" for BTB diagnosis. However, the long period required for the isolation and biochemical identification, is a limitation because it may require more than twelve weeks to complete the final diagnosis, and also low sensitivity (Collins et al., 1994). The collected samples are subjected to decontamination by the addition of $\mathrm{NaOH}, \mathrm{H}_{2} \mathrm{SO}_{4}$, oxalic acid, or quaternary ammonium compounds, to eliminate competitive microorganisms (Ambrosio et al., 2008; Medeiros et al., 2010; Young et al., 2005). 
Unfortunately, the toxic effects of these substances may affect mycobacterial viability, thereby interfering with culturing the organism.

The immunological diagnosis of BTB is based on delayed-type hypersensitivity (DTH) reaction in vivo, represented by the tuberculin skin test (TST) (Schiller et al., 2010). This is an indirect method of diagnosis of TB and can reveal incipient infections, with three to eight weeks after contact with the M. bovis. It is a widely used test recommended by Robert Koch in 1890 (Monaghan et al., 1994). However, it has low sensitivity and in individuals vaccinated with Bacillus Calmette-Guerin (BCG), it is often associated with a false-positive result due to cross-reactive immune responses to antigens common to MTB. The response of T-cells to these proteins is a measurable secretion of interferon $\gamma$ (IFN- $\gamma$ ) (Gursimran et al., 2016).

The T.B. FERON test is a test for Cell Mediated Immune (CMI) responses to peptide antigens that simulate mycobacterial proteins. These proteins (ESAT-6, CFP-10, and TB7.7) are absent from all BCG strains and from most non-tuberculous mycobacteria with the exception of $M$. kansasii, $M$. szulgai and M. marinum. Individuals infected with $M$. tuberculosis complex organisms (M. tuberculosis, $M$. bovis, M. africanum, M. microti, $M$. canetti) usually have lymphocytes in their blood that recognize these and other mycobacterial antigens. This recognition process involves the generation and secretion of the cytokine, IFN- $\gamma$. The detection and subsequent quantification of IFN- $\gamma$ forms the basis of this test (Ferrara, 2005)

Molecular biology techniques are widely applicable to laboratory diagnosis of infectious diseases caused by bacteria (Cortez et al., 2006). Faster diagnosis of TB are of significant clinical importance, therefore, PCR have been proposed for the rapid detection of small amount of $M$. bovis DNA (de Kantor and Ritacco, 2006). This study aimed to evaluate the use of both Tuberculin test and T.B. Feron for the diagnosis of bovine tuberculosis in different localities. The utilization of T.B. FERON test to differentiate between vaccinated and infected cattle was assessed.

\section{MATERIALS AND METHODS}

\section{Animals}

The study was conducted on 3 farms in Behera, Matrouh and Dakahlya Governorates. The farms included in the study had no previous records on animals with confirmed $M$. bovis infection because the herd was previously tested with skin test. A total of 1323 animals of one year old and above were included in the study. Verbal approval from the farm owners was taken for the participation in the study.

\section{Tuberculin test}

Mammalian PPD tuberculin was prepared by Bacterial Diagnostic Products Research Department, Veterinary Serum and Vaccine Research Institute (VSVRI), Abbassia, Cairo, Egypt. All the animals were subjected to comparative cervical intradermal tuberculin test as per the guidelines from the World Organization for Animal Health (OIE). Briefly, the test was carried out in the middle third of the neck of each animal where avian tuberculin PPD-2500 (PPDA) (Prionics) and bovine tuberculin PPD-3000 antigens (PPD-B) (Prionics) were injected (i.e., 0.1 $\mathrm{ml}$ of PPD) in two sites of neck $12 \mathrm{~cm}$ apart. Skin thicknesses were measured with caliper before and 72 hour after PPD injections. The result is expressed as:

(A) Positive reactor: Difference of the skin thickness at the injection sites is at least $4 \mathrm{~mm}$ or greater, (B) negative reactor: No reaction to the bovine antigen or the difference of the skin thickness at the injection sites does not exceed $2 \mathrm{~mm}$, while (C) inconclusive reaction: Reaction to both $\mathrm{PPD}-\mathrm{B}$ and $\mathrm{PPD}-\mathrm{A}$ exceeded $2 \mathrm{~mm}$, but the difference between the bovine and avian reaction was $<4 \mathrm{~mm}$. (AwahNdukum, 2016).

\section{T.B FERON Test}

Blood samples from tuberculin positive animals $(n=357)$ were collected from the jugular vein in commercially available sterile $10 \mathrm{ml}$ heparinized tubes, heparin as anti-coagulant and gentle mix blood by inversion several times to dissolve the heparin.

Blood samples should be transported to the laboratory at room temperature $\left(22 \pm 3^{\circ} \mathrm{C}\right.$, avoid extremes). The immunoassay was performed using T.B. FERON- kit from (BIONOTE, Inc., USA) according to the manufacturer's instructions. Briefly, in this test system, $1.5 \mathrm{ml}$ aliquots of heparinized blood were dispensed into individual wells of 24-well tissue culture plates and incubated with $100 \mu \mathrm{l}$ each of stimulating antigens (PPD-B and PPD-A) and PBS (non-stimulating control) for $16-24 \mathrm{~h}$ at $37^{\circ} \mathrm{C}$ in a humidified atmosphere with $5 \% \mathrm{CO}_{2}$. The plasma was then collected and assayed for $\gamma$-IFN production in duplicate at $\mathrm{OD}=450 \mathrm{~nm}$. (Schiller et al., 2010).

\section{Bacteriological examination}

Positive animals by both tuberculin and T.B FERON tests were slaughtered for PM and some samples were taken for bacteriological examination on specific media. Lymph node samples were initially cut into cubes $(5 \mathrm{~mm} \times 5 \mathrm{~mm})$. Cubed lymph node sample (approx.10 g) was ground with a small amount of sterile sand using a mortar and pestle before the addition of $12 \mathrm{ml} \mathrm{5 \%}$ oxalic acid (Stewart et al., 2013). The sample was mixed again and the liquid content transferred to a centrifuge tube, discarding the remaining solid material from the mortar. The sample was transferred to a rotary mixer and mixed for 15 min at $37^{\circ} \mathrm{C}$, followed by centrifugation at $1.620 \times \mathrm{g}$ 
for $15 \mathrm{~min}$. The supernatant was discarded and the sediment washed twice in sterile phosphate buffered saline (PBS). Using a sterile swab, the sediment was streaked directly onto Löwenstein-Jensen media. The samples were incubated at $37^{\circ} \mathrm{C}$ for 90 days with weekly examination. The isolation of $M$. bovis was carried out in a class II biological safety Type A2 cabinet.

Molecular identification by real time PCR

Suspected colonies were identified by performing a real time PCR using MTplexdtec-RT-qPCR Test (Akhtar et al., 2015). That comprises a series of species-specific targeted reagents designed for detection of all species contained in the Mycobacterium tuberculosis complex. DNA extraction from the isolates was performed using Bacterial DNA extraction kit (BioTeke Corporation, Shanghai, China) according to the manufacturers' guidelines. Extracted DNA from the suspected cultures was subjected to real-time PCR using MTplexdtec-RT-qPCR Test. The primers and TaqMan probe target a sequence conserved for all strains of each single species belonging to Mycobacterium tuberculosis complex.

\section{RESULTS}

Table 1:

\begin{tabular}{|c|c|c|c|c|c|}
\hline \multirow[t]{2}{*}{ Farm No } & \multirow{2}{*}{$\begin{array}{c}\text { Total No. of Animals tested } \\
\text { tuberculin }\end{array}$} & \multicolumn{2}{|c|}{$\begin{array}{c}\text { Positive } \\
\text { Tuberculine test }\end{array}$} & \multicolumn{2}{|c|}{$\begin{array}{c}\text { positive } \\
\text { T.B. FERON test }\end{array}$} \\
\hline & & No. & $\%$ & No. & $\%$ \\
\hline Farm 1 & 120 & 79 & 6 & 46 & 3.5 \\
\hline Farm 2 & 520 & 274 & 20.7 & 166 & 12.5 \\
\hline Farm 3 & 683 & 4 & 0.3 & 0 & 0 \\
\hline Total No. & 1323 & 357 & 27 & 212 & 16 \\
\hline
\end{tabular}

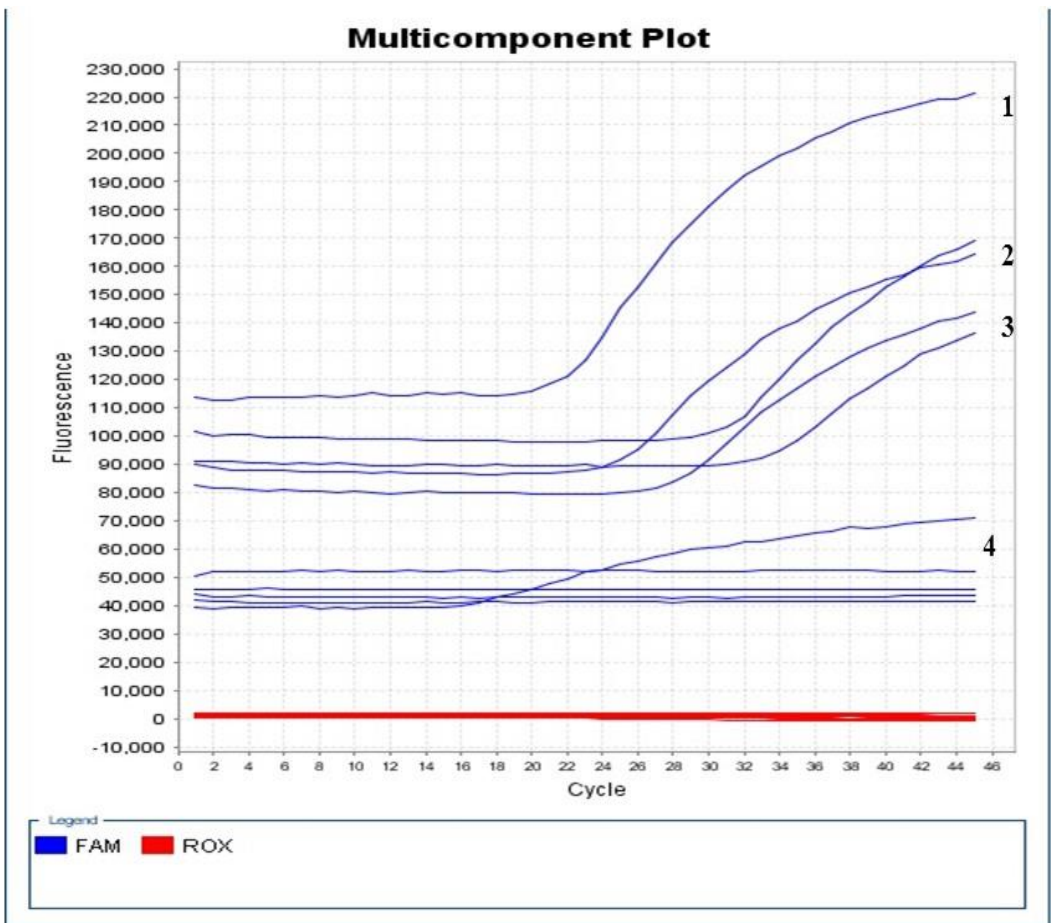

Figure 1: Amplification curve of Mycobacterium complex rtPCR (1: undiluted positive control, 2: duplicate of 2 fold dilution of sample1, 3: duplicate of 2 fold dilution of sample 2, 4: five reactions of negative controls). 


\section{DISCUSSION}

The results in Table (1) revealed that out of 1323 cattle tested, 357 (27\%) were positive by tuberculin test. The results of bovine gamma-interferon $(\gamma$-IFN) enzyme immunoassay, revealed $212(16 \%)$ positive animals. in the first farm the tested cattle were 120 animals and the positive were $79(6 \%)$ by tuberculin test, then tested by bovine gamma-interferon ( $\gamma$-IFN) enzyme immunoassay, the positive were 46 (3.5\%), the second farm the tested cattle were 520 and the positive reactors for tuberculin test were 274 (20.7 $\%)$, then tested by bovine gamma-interferon $(\gamma$-IFN) enzyme immunoassay, the positive were $166(12.5 \%)$ and the third farm the tested cattle were 683 and the positive cases were 4 animals $(0.3 \%)$ by tuberculin test, then tested by bovine gamma-interferon ( $\gamma$-IFN) enzyme immunoassay and all the samples gave negative results.

Since 2006, the $\gamma$ - IFN assay is an assay through which it is possible to verify the existence of cellmediated immune response developed by the body of the animal in response to mycobacterial infection. $\gamma$ IFN produced by $\mathrm{T}$ - lymphocytes of the infected animal is detected, using monoclonal anti- $\gamma$ IFN. The lack of detection of $\gamma$-IFN characterizes the negativity of the animals to infection $M$. bovis since lymphocytes from uninfected cattle do not produce this cytokine in specific ways. As this is an in vitro test that has the advantage of not interfering with the immune status of the animal and may be repeated in the same animal is the need to respect the period of desensitization. This assay showed the increase in the sensitivity and the possibility of more rapid repeat testing, no need for a second visit to the farm and more objective test procedures and interpretation in comparison to the tuberculin test (Faye et al., 2011; Neill et al., 1994; Schiller et al., 2010).

The strategic application of the $\gamma$ IFN assay, as an adjunct to the tuberculin test, can facilitate the early removal of infected animals in herds. The objective of the assay is to identify high-risk animals that are potentially infectious for other cattle can generate confidence in herd-owners that rational decisions can be made based on sound scientific principles, and that effective schemes can be devised to make more rapid progress in the elimination of the infection from affected herds (Schiller et al., 2010).

The assay is based on the release of $\gamma$ IFN from sensitized lymphocytes during a 16-24 hours incubation period with specific antigen and makes use of comparison of $\gamma$ IFN production following stimulation with avium and bovine PPD (Alito et al., 2003; de la Rua-Domenech et al., 2006; Schiller et al., 2010; Vordermeier et al., 2008). M. tuberculosis complex specific antigens have also been used to improve $\gamma$ IFN assay specificity, especially in population groups testing positive to the tuberculin test. The use of these antigens may also offer the ability to differentiate BCG-vaccinated from unvaccinated animals. (Faye et al., 2011; Fentahun and Luke, 2012).

Our results coincide with that reported by Ryan et al. (2000) who reported that, in cattle, the sensitivity and specificity of the gamma- IFN test for diagnosis of $M$. bovis was 85 and 93\%, respectively, when compared with the caudal fold test. No significant differences in the sensitivity and specificity of the test were observed between blood samples that were cultured on the day of collection and those cultured the day after collection. These findings support the use of the gamma -IFN test as a practical test that can be used to complement the caudal fold skin test.

The results of bacteriological examination of lymph nodes from positive cases with both T.B. FERON and tuberculin tests revealed that all the samples were positive by culture technique and the identified species was $M$. bovis. Confirmation of the isolates by real time PCR showed positive reactions (Figure 1).

In accordance, Tyler et al. (2011) reported that culture of $M$. bovis from diagnostic specimens is the gold standard for the diagnosis of bovine tuberculosis in USA. Detection of $M$. bovis by PCR in tissue homogenates may provide a simple rapid method to complement bacterial culture. A significant impediment to PCR based assays on tissue homogenates is specificity since mycobacteria other than $M$. bovis may be associated with the tissues. Also, Wessam Youssef et al. (2017) examined a total of 49 specimens collected from four major abattoirs (El-Basateen- El-Monieb- Beni-SuefAl-fayoum) to be analyzed bacteriologically and biochemically for the isolation, identification and confirmation of $M$. bovis with molecular methods. Only 19 isolates were found to be positive slowgrowers Mycobacterium species by conventional cultivation method on solid medium and were identified biochemically to $17 \mathrm{M}$. bovis isolates and 2 isolates M. tuberculosis.

Despite all the efforts to control BTB, the disease persists, with serious implications. This zoonotic disease constitutes a significant economic burden to the agricultural industries and for human health. Eradication programs based on tuberculin testing and subsequent slaughter of positive animals have been reported successful in many developed countries. However, tuberculin test is limited in its specificity and sensitivity, therefore, culture should be used to confirm the presence of $M$. bovis. Molecular techniques such as PCR can also detect $M$. bovis directly in clinical samples. Many factors contribute to the persistence of BTB, such as the limitations of diagnostic tests (concerning both sensitivity and specificity), larger herd sizes, increase 
in animal movements and trade, and limited options for control, such as limitations on whole herd depopulation (Wessam Youssef et al., 2017).

\section{CONCLUSION}

In conclusion, considering the current trends associated with BTB control and eradication programs, it is important to increasingly focus resources to target control strategies based on more effective diagnostic methods. Hence, the use of TBFeron for detection of BTB is more useful.

\section{REFERENCE}

Akhtar F.; Javed M.T.; Aziz-ur Rehman aktar P.; Hussain S.M. Aslam M.S.; Kausar R.; Qamar M. and Cagiola M. (2015): The use of PCR technique in the identification of Mycobacterium species responsible for bovine tuberculosis in cattle and buffaloes in Pakistan. Trop Anim Health Prod.

Alito, A.; Mcnair, J.; Girvin, R.M.; Zumarraga, M.; Bigi, F.; Pollock, J.M. and Cataldi, A. (2003): Identification of Mycobacterium bovis antigens by analysis of bovine $\mathrm{T}$-cell responses after infection with a virulent strain Brazilian Journal of Medical and Biological Research, vol. 36, no. 11, pp. 1523-1531.

Ambrosio, S.R.; Oliveira, E.M.D.; Rodriguez, C.A.R.; Ferreira Neto, J.S. and Amaku, M. (2008): Comparison of three decontamination methods for isolation. Mycobacterium bovisBrazilian Journal of Microbiology, vol. 39, no. 2, pp. 241-244.

Collins, D.M.; Radford, A.J.; De Lisle, G.W. and Billman-Jacobe, H. (1994): Diagnosis and epidemiology of bovine tuberculosis using molecular biological approaches. Veterinary Microbiology, vol. 40, no. 1-2, pp. 83-94.

Collins, J.D. (2006): Tuberculosis in cattle: strategic planning for the future. Veterinary Microbiology, vol. 112, no. 2-4, pp. 369-381.

Cortez, A.; Castro, AMMG; Heinemann, MB.; Soares, RM.; Leite, RC.; Scarcelli, E.; Genovez, ME.; Alfieri, AA. and Richtzenhain, LJ. (2006): Detecção de ácidosnucléicos de Brucella spp., Leptospira spp., herpesvirusbovino e vírus da diarréia viral bovina, emfetosbovinosabortados e emanimaismortos no perinatal. Arq Bras Med Vet Zootec.; 58: 1226-1228.

De La Rua-Domenech, R.; Goodchild, A.T.; Vordermeier, H.M.; Hewinson, R.G.; Christiansen, K.H. and Clifton-Hadley, R.S. (2006): diagnosis of tuberculosis in cattle: a review of the tuberculin tests, gammainterferon assay and other ancillary diagnostic techniques. Ante mortemResearch in
Veterinary Science, vol. 81, no. 2, pp. 190210.

Faye, S.; Moyen, J.L.; Gares, H.; Benet, J.J.; GarinBastuji, B. and Boschiroli, M.L. (2011): Determination of decisional cut-off values for the optimal diagnosis of bovine tuberculosis with a modified IFNgamma assay (Bovigam ${ }^{\circledR}$ ) in a low prevalence area in France. Veterinary Microbiology, vol. 151, no. 1-2, pp. 60-67.

Fentahun, T. and Luke, G. (2012): Diagnostic techniques of bovine tuberculosis: a review. African Journal of Basic and Applied Sciences, Vol. 4, No. 6, pp. 192-199.

Ferrara, G.; Dany, A.E. and Moris, A. (2005): Routine hospital use of commercial whole blood interferon- gamma assay for tuberculosis infection. Am J RespirCrit Care Med, 2005. 172: 631-5.

Gursimran Filia, Geeta Devi Leishangthem, Vishal Mahajan and Amarjit Sing (2016): Detection of Mycobacterium tuberculosis and Mycobacterium bovis in Sahiwal cattle from an organized farm using ante-mortem techniques Vet World. 2016 Apr; 9(4): 383387.

Awah-Ndukum, J. (2016): Interpretation Criteria for Comparative Intradermal Tuberculin Test for Diagnosis of Bovine Tuberculosis in Cattle in Maroua Area of Cameroon Veterinary Medicine International Volume 2016.

Khalili Tahereha; Nakhaee Alirezab; Salehi Massouda and Kariminia Aminac, A. (2010): Validity study of the QuantiFERON-TB Gold (QFT-TB) method for the diagnosis of pulmonary tuberculosis in a high risk population SWISSMEDWKLY 2010; 140 (56): 95-96

Mederios, L.S.; Marassi, C.D.; Figueiredo, E.E. and Lilenbaum, W. (2010): Potential application of new diagnostic methods for controlling bovine tuberculosis in Brazil. Brazilian Journal of Microbiology, Vol. 41, No. 3, pp. 531-541.

Monaghan, M.L.; Doherty, M.L.; Collins, J.D.; Kazda, J.F. and Quinn, P.J. (1994): The tuberculin test. Veterinary Microbiology, vol. 40, no. 1-2, pp. 111-124.

Neill, S.D.; Cassidy, J.; Hanna, J.; Mackie, D.P.; Pollock, J.M.; Clements, A.; Walton, E. and Bryson, D.G. (1994): Detection of Mycobacterium bovis infection in skin testnegative cattle with an assay for bovine interferon-gamma. The Veterinary Record, vol. 135 , no. 6 , pp. 134-135

Rossau, R.; Traore, H.; De Beenhouwer, H.; Mijs, W.; Jannes, G.; De Rijk, P. and Portaels, F. (1997): Evaluation of the INNO-LiPA Rif. TB assay, a reverse hybridization assay for the simultaneous detection of Mycobacterium tuberculosis complex and its resistanceto 
rifampin. Antimicrob Agents Chemother.41: 2093-2098. [Pub Med]

Ryan, TJ.; Buddle, BM. and De Lisle, GW. (2000): An evaluation of the gamma interferon test for detecting bovine tuberculosis in cattle 8 to 28 days after tuberculin skin testing. Res Vet Sci. Aug; 69(1): 57-61.

Schiller, I.; Oesch, B.; Vordermeier, H.M.; Palmer, M.V.; Harris, B.N.; Orloski, K.A.; Buddle, B.M.; Thacker, T.C.; Lyashchenko, K.P. and Waters, W.R. (2010): Bovine tuberculosis: areview of current and emerging diagnostic techniques in view of their relevance for disease control and eradication. Transboundary and Emerging Diseases, vol. 57, no. 4, pp. 205-220.

Stewart, L.D.; McCallen, L.; Gordon, A. and Grant, I.R. (2013): improved detection of mycobacterium bovis infection in bovine lymph node tissue using immunomagnetic separation based methods. PLOS one 8 (3), e58374

Tyler C. Thacker; Beth Harris; Mitchell V. Palmer and Wade R. Waters (2011): Improved specificity for detection of Mycobacterium bovis in fresh tissues using IS6110 real-time
PCR. BMC Vet. Res.7: 50. Published online 2011 Aug 25. doi: 10.1186/1746-6148-7-50

Une, Y. and Mori, T. (2007): Tuberculosis as a zoonosis from a veterinary perspective. Comparative Immunology, Microbiology and Infectious Diseases, vol. 30, no. 5-6, pp. 415425.

Vordermeier, H.M.; Whelan, A. and Hewinson, G. (2008): The scientific case for the gamma interferon "BOVIGAM" ${ }^{\text {TM" }}$ assay. Government Veterinary Journal, vol. 19, pp. 38-43.

Wessam Youssef; Khaled Al-Amry; Nashwa Helmy; Salah El Deen Abdel Karim and Sherif Marouf (2017): Comparative Study Between Traditional Methods and Molecular Methods in Diagnosis of Bovine Tuberculosis.American Journal of Microbiology and Biotechnology Vol.4, No. 6, Publication Date: Oct. 13, 2017, Page: $83-90$.

Young, J.S.; Gormley, E. and Wellington, E.M. (2005): Molecular detection of Mycobacterium bovis and Mycobacterium bovis BCG (Pasteur) in soil. Applied and Environmental Microbiology, Vol. 71, No. 4, pp. 1946-1952.

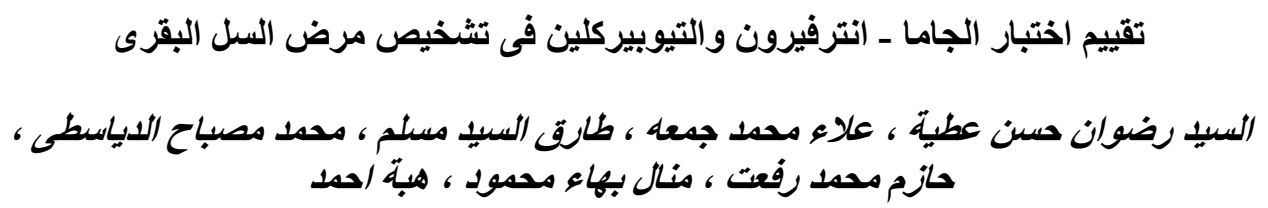

E-mail: tarekelsayedmosallam@yahoo.com Assiut University web-site: www.aun.edu.eg

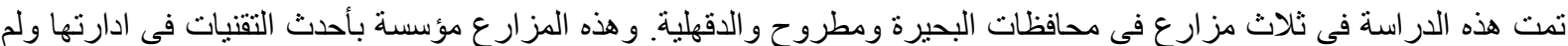

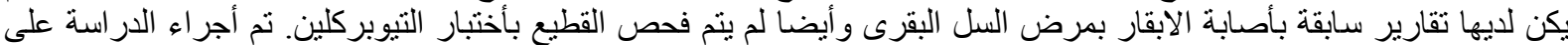

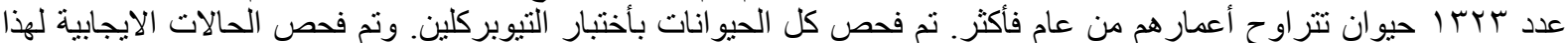

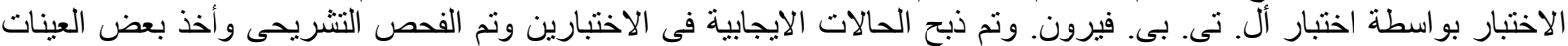

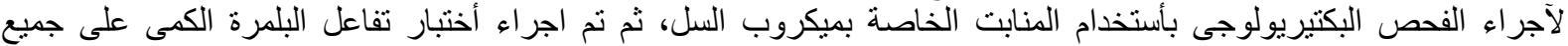

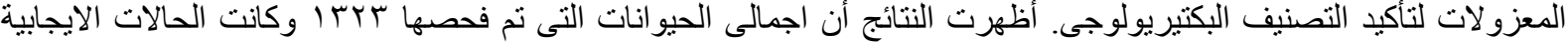

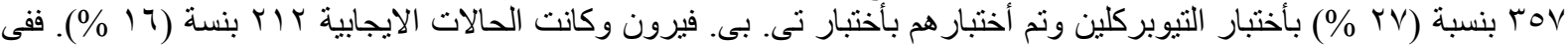

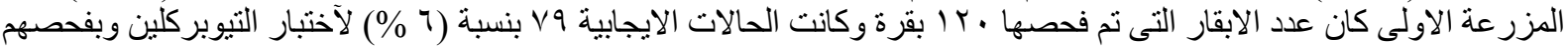

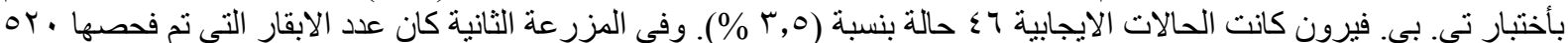

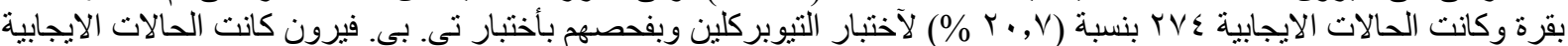

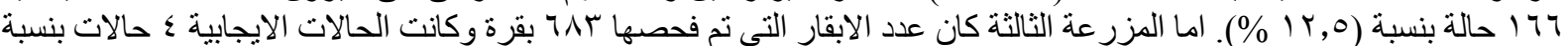

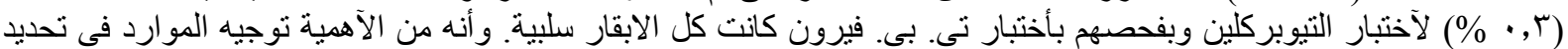

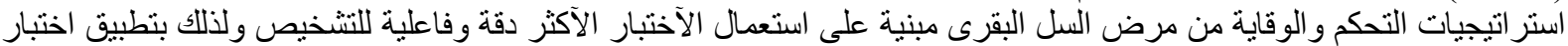

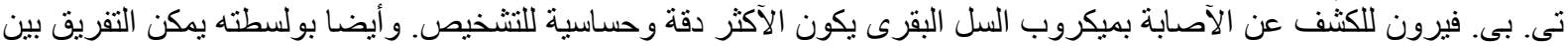
الآبقار المصابة و الآخرى المحصنة. 